\title{
Happiness and heart rate response: a case of fan services at japanese professional baseball games
}

\author{
Kohzoh Yoshino*, Sayaka Matsumoto, Eiichi Someya, Muneo Kitajima \\ Center for Service Research, National Institute of Advanced Industrial Science and Technology (AIST), Midorigaoka, Ikeda, Osaka, \\ Japan; ${ }^{*}$ Corresponding Author: yoshino-k@aist.go.jp
}

Received 19 November 2010; revised 22 December 2010; accepted 25 December 2010.

\begin{abstract}
The aim of this study was to develop a method for predicting the psychological states of spectators watching professional baseball games at a stadium. This method includes a real time measurement of instantaneous heart rate (i.e., the inverse of the RR interval) without preventing the subject from watching the game and a mathematical procedure used to predict moment by moment psychological states by correlating the degree of a psychological state with the strength of heart rate response, defined as the mean deviation of heart rate variability from a linear regression line from $5 \mathrm{sec}$ before to 25 sec after an event during a baseball game. We recorded the instantaneous heart rates of 10 subjects (total of 27 cases) while they watched Japanese professional baseball games at a stadium and had them subjectively rate the degree of their psychological states in an after-event interview. We identified three psychological states (happiness, excitement, and vigor) whose strength can be predicted from the strength of heart rate response. Analysis of the measured data clarified that heart rate response had a significant correlation with the subjective rating of the intensity of happiness $(r=0.56, p<0.0001)$, vigor $(r=0.55, p<0.0001)$, and excitement $(r=$ $0.49, p<0.0001)$.
\end{abstract}

Keywords: Sports Entertainment; Physiological Signal; Heart Rate; Happiness; Excitation

\section{INTRODUCTION}

One of the most important goals of sports entertainment services, such as professional baseball game services, is to enhance the happiness of spectators at the stadium. To this end, it is important to measure how the spectator psychologically responds to each event at the stadium, and to develop a method to use the data to achieve this goal. Human psychological states can be measured in two ways. One is on-site measurement, in which the spectators report their psychological states by filling out questionnaires or by verbally describing them. The other is after-event interviews in which they are asked to remember their psychological state during the event in baseball game [1,2]. Since these methods are easy to carry out, they have been used widely. However, each method has a problem. One is that the on-site measurement is likely to interfere with spectators' watching of games. The other is that the after-event measurement may not be reliable due to interviewees' failure to remember or to their psychological biases [3,4]. In this paper, the use of an on-site physiological measurement that does not interfere with spectators' watching of games and a method to relate the physiological data with spectators' psychological states is proposed.

Physiological signals such as heart rate reflect the autonomic nervous system's activity [5]. The autonomic nervous system is strongly affected by such psychological states as excitement. Thus, it may be possible to use heart rate (physiological signals) to evaluate psychological states [6-9]. The use of physiological signals has two advantages over the conventional method. The first is a relatively unobtrusive and automatic measurement of psychological states in real time without interfering with the spectators' watching of games, and the second is a continuous measurement of their variability.

To our knowledge, no study thus far has clarified the correlation between the physiological response and the psychological state of a spectator watching a professional game at a stadium. We hypothesize that heart rate increases when a spectator becomes happy and excited by such events as the favored team's scoring and appealing fan service events while it decreases when a spectator becomes depressed by events such as the opposing team's scoring and boring fan service events. For this study, we recorded the instantaneous heart rates of 
subjects while they watched a Japanese professional baseball game at a stadium. We analyzed how their heart rate responses to events during games correlated with their subjective psychological states.

\section{METHODS}

Ten subjects (five females and five males between the ages of 21 and 53 years) participated in the on-site physiological data collection sessions, after providing their informed written consent approved by the ethical committee at AIST. All subjects were fans of the Hokkaido Nippon-Ham Fighters, a Japanese professional baseball team, and had been to the Sapporo Dome to watch Fighters' games 28 to 250 times.

Subjects watched Fighters' games at the Sapporo Dome. We collected physiological data while they watched the games. Eight subjects watched three games (one in July, one in August, and one in September of 2008); one subject watched one game in September of 2008; and one watched two games in July and August of 2008. We collected a total of 27 cases. All subjects were seated in the infield zone. We recorded their RR-intervals with a wearable electrocardiogram device (ActiveTracer, AC-301, GMS, Japan), from about $5 \mathrm{~min}$ before the start of the game until $10 \mathrm{~min}$ after the end of the game. Typically, the length of a baseball game is $180 \mathrm{~min}$.

We also recorded video images of each subject's behavior. Subjects watched their video images on a separate day and recalled their subjective psychological states at specific events as they watched the games. The specific events were the Fighters' and opponents' scoring and four fan service events. The four fan service events were two types of dancing exhibitions, the Fighters' cheering song, and a show by the Fighters' mascot. The subjects registered the intensity of their psychological states on a $100 \mathrm{~mm}$-long visual analogue scale (VAS) questionnaire, for which the end points were labeled "lowest" and "highest". The questionnaire quantified the intensity of eight psychological states: happiness, tension, fatigue, boredom, depression, anger, vigor, and excitement. Tension, fatigue, depression, anger, and vigor are scales on the well-known Profile of Mood States (POMS) questionnaire [10]. In addition to these scales, we adopted the scales happiness, boredom, and excitement since these intensities vary greatly in an entertainment environment. To reduce inter-individual variability, we normalized the measured values of psychological state intensity by transforming the data to a z-score for each subject.

Figure 1 presents an example of the time course of a subject's heart rate from the beginning to the end of a game. Clearly, heart rate increased when the Fighters scored.

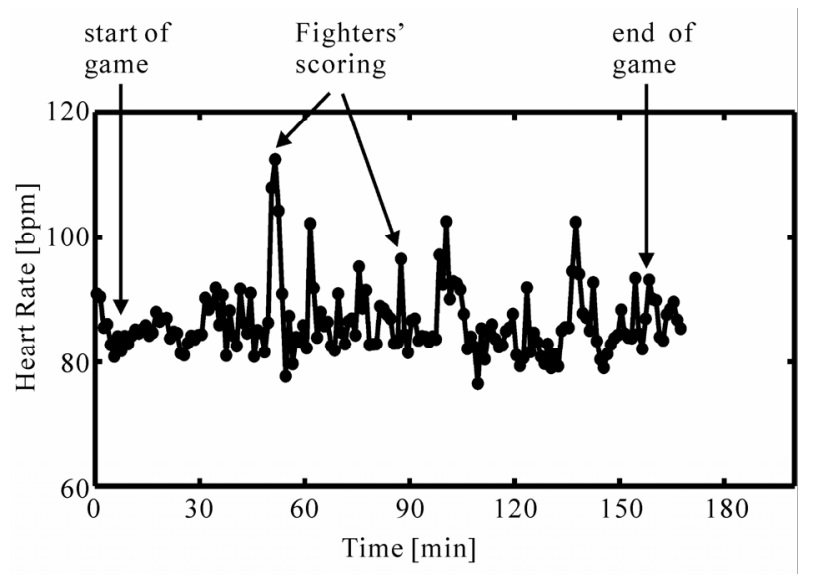

Figure 1. Example of the time course of a subject's heart rate from the beginning to the end of a game. Heart rate increased when the Fighters scored.

We fitted a linear regression line to the time course of heart rate measured from the beginning to the end of a game and then calculated the heart rate response to specific events. The heart rate response was defined as the mean deviation of heart rate variability from a linear regression line from $5 \mathrm{sec}$ before to $25 \mathrm{sec}$ after an event during a game. The heart rate responses to Fighters' and opponents' scoring and to four fan service events (two types of dancing exhibitions, the Fighters' cheering song and a show by the Fighters' mascot) were calculated. The correlation coefficients of the heart rate responses to the specific events and z-scored psychological state scores were calculated. The grand mean value of heart rate response to scoring events in July of 2008 was then compared with those in August and September of 2008. We also analyzed how fan career, measured by the total number of past visits to Sapporo Dome to watch Fighters' games affected the subject's heart rate responses to scoring events.

\section{RESULTS}

Table 1 summarizes the correlation coefficients between heart rate responses to scoring and fan service events and z-scored subjective psychological state intensities. Figure 2 shows the scatter plots from comparing heart rate response to scoring and fan service events with the corresponding subjectively evaluated normalized intensity of happiness. Heart rate responses indicated significant positive correlations with the subjective evaluation of happiness $(\mathrm{r}=0.56, \mathrm{p}<0.0001)$ (Figure 2). Moreover, it indicated significant positive correlations with vigor $(\mathrm{r}=0.55, \mathrm{p}<0.0001)$ and excitement $(\mathrm{r}=$ $0.49, \mathrm{p}<0.0001)$.

The grand mean heart rate response to Fighters' scoring in July of 2008 (12.95 bpm) was twice as high as 


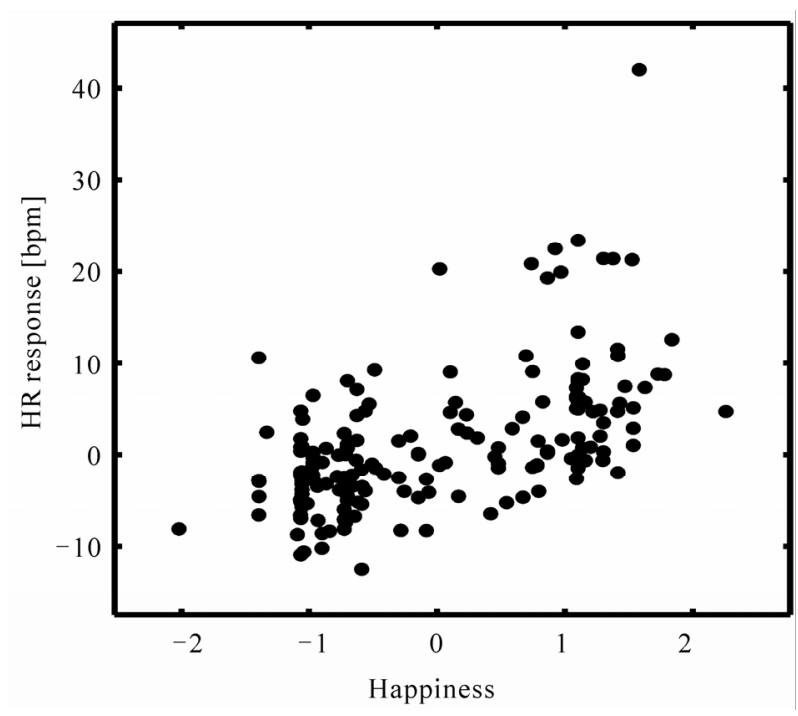

Figure 2. Scatter plots comparing heart rate (HR) response to scoring and fan service events with the corresponding subjectively evaluated intensity of happiness ( $\mathrm{z}$-scored) $(\mathrm{r}=0.56, \mathrm{p}<$ 0.0001 ).

Table 1. Correlation coefficient between heart rate (HR) responses to scoring and fan service events and the corresponding subjectively evaluated intensity of psychological states (z-scored). ${ }^{*}: \mathrm{p}<0.0001$.

\begin{tabular}{cc}
\hline & Correlation coefficient \\
\hline Happiness & $0.56^{*}$ \\
Tension & 0.07 \\
Fatigue & -0.23 \\
Boredom & $-0.29^{*}$ \\
Depression & $-0.43^{*}$ \\
Anger & $-0.33^{*}$ \\
Vigor & $0.55^{*}$ \\
Excitement & $0.49^{*}$
\end{tabular}

those in August (4.92 bpm) and September of 2008 (6.29 bpm). The heart rate increase response when the Fighters scored was likely to decrease as the total number of past visits to Sapporo Dome to watch Fighters' games increased (Table 2).

\section{DISCUSSION}

This study aimed to develop a new method that uses a physiological signal (heart rate) to assess the psychological state of a spectator watching a professional baseball game in a stadium. Analysis of the measured data clarified that heart rate response had a significant correlation with the subjectively rated intensity of happiness, vigor, and excitement (Table 1 and Figure 2). This result suggests that it may be possible to predict automatically a spectator's happiness, vigor, and excitement in response to each event at a stadium automatically and in real time by simply measuring instantaneous heart rate. The grand mean heart rate response to Fighters' scoring in July of 2008 (12.95 bpm) was twice as high as those in August (4.92 bpm) and September of $2008(6.29 \mathrm{bpm})$. Fighters were in contention for the league championship in July of 2008 but fell behind the competition in August and September of 2008. Moreover, the game schedule overlapped the Olympic Games in Beijing in August of 2008. These factors may have resulted in the decreased excitement in supporting the team's scoring event.

Heart rate response to Fighters' scoring tended to decrease as the total number of past visits to Sapporo Dome to watch Fighters' games increased (Table 2). This result implies that responses to scoring became duller as fan career matured. Thus, it is necessary to take fan career into account when using heart rate responses to evaluate a spectator's psychological state.

Several limitations pertain to this study. First, the number of subjects was small. Second, all subjects were seated in the infield zone for this experiment. Therefore, half of the subjects who usually watch games from the outfield zone did not watch the games from their usual standing position. Third, subjects did not watch the games with their usual companions. In order to apply the results of this study to baseball entertainment services, data should be collected in a more typical situation. The limitations of the present study will be addressed in our future work.

In summary, the results of this study show that the heart rate response of spectators has a significant correlation with the subjective rating of the intensity of happiness, vigor, and excitement in the field of professional

Table 2. Dependence of the heart rate (HR) responses to Fighters' and opponents' scoring on the total number of past visits to Sapporo Dome to watch Fighters' games.

\begin{tabular}{|c|c|c|c|c|c|c|c|c|c|c|}
\hline & $\mathrm{S} 1$ & $\mathrm{~S} 2$ & $\mathrm{~S} 3$ & $\mathrm{~S} 4$ & S5 & S6 & S7 & S8 & S9 & $\mathrm{S} 10$ \\
\hline HR response to Fighters' scoring & 5.4 & 3.6 & 1.6 & 14.0 & 11.6 & 7.7 & 11.4 & 7.2 & 11.2 & 14.8 \\
\hline HR response to opponents' scoring & -1.4 & -4.7 & 0.3 & -3.4 & -6.6 & -2.7 & -2.7 & -3.2 & -1.5 & -0.3 \\
\hline Total number of past visits & 250 & 153 & 120 & 64 & 50 & 48 & 42 & 36 & 31 & 28 \\
\hline
\end{tabular}


baseball entertainment.

\section{ACKNOWLEDGEMENTS}

This research was supported by the Ministry of Economy, Trade and Industry (METI). The authors express their gratitude to collaborating company Hokkaido Nippon-Ham Fighters for their helpful discussions and for providing experimental field space. We also thank Dr. M. Mochimaru and Dr. K. Naito of the National Institute of Advanced Industrial Science and Technology (AIST) for their helpful discussions.

\section{REFERENCES}

[1] Caro, L.M. and Garcia, J.A.M. (2007) Cognitive-affective model of consumer satisfaction. An exploratory study within the framework of a sporting event. Journal of Business Research, 60, 108-114. doi:10.1016/j.jbusres.2006.10.008

[2] Leeuwen, L.V., Quick, S. and Daniel, K. (2002) The sport spectator satisfaction model: A conceptual framework for understanding the satisfaction of spectators. Sport Management Review, 5, 99-128. doi:10.1016/S1441-3523(02)70063-6

[3] Bower, G. (1981) Mood and memory. American Psychologist, 36, 129-148. doi:10.1037/0003-066X.36.2.129

[4] DeVries, M. (1992) The experience of psychopathology.
Cambridge University Press, Cambridge. doi:10.1017/CBO9780511663246

[5] Akselrod, S., Gordon, D., Ubel, F.A., Shannon, D.C., Barger, A.C. and Cohen, R.J. (1981) Power spectrum analysis of heart rate fluctuation: A quantitative probe of beat-to-beat cardiovascular control. Science, 213, 220-222. doi:10.1126/science.6166045

[6] Andreassi, J.L. (2006) Psychophysiology. Human behavior \& physiological response. 5th Edtion, Lawrence Erlbaum Associates, New Jersey.

[7] Murata, J., Matsukawa, K., Shimizu, J., Matsumoto, M., Wada, T. and Ninomiya, I. (1999) Effects of mental stress on cardiac and motor rhythms. Journal of the Autonomic Nervous System, 75, 32-37. doi:10.1016/S0165-1838(98)00171-4

[8] Ohsuga, M., Shimono, F. and Genno, H. (2001) Assessment of phasic work stress using autonomic indices. International Journal of Psychophysiology, 40, 211-220. doi:10.1016/S0167-8760(00)00189-6

[9] Yoshino, K., Edamatsu, M., Yoshida, M. and Matsuoka, K. (2007) An algorithm for detecting startle state based on physiological signals. Accident Analysis \& Prevention, 39, 308-312.doi:10.1016/j.aap.2006.08.003

[10] McNair, D.M., Lorr, M. and Droppleman, L.F. (1992) Profile of mood states. Educational and Industrial Testing Service, San Diego. 